American Journal of Applied Sciences 9 (4): 459-467, 2012

ISSN 1546-9239

(C) 2012 Science Publications

\title{
Discussion around the Scattering Matrix Realization of a Microwave Filter using the Bond Graph Approach and Scattering Formalism
}

\author{
${ }^{1}$ Hichem Taghouti and ${ }^{1,2}$ Abdelkader Mami \\ ${ }^{1}$ Department of Electrical Engineering, \\ Laboratory of Analysis and Command of the Systems, \\ ENIT-BP 37, 1002 Tunis Le BELVEDERE, Tunisia \\ ${ }^{2}$ Department of Physics, \\ Faculty of Sciences of Tunis, Electronic Laboratory, 2092 El Manar Tunisia
}

\begin{abstract}
Problem statement: Further to research works made previously and which use collectively the scattering formalism and bond graph technique for the modeling of a physical systems often working in high frequencies, we propose, in this article, a comparative study (discussion) for the scattering matrix realization of a high-frequency physical system. Approach: This discussion is based, on the one hand, on a non-causal (acausal) bond graph model which represents the starting model for the determination of the scattering parameters. On the other hand, we shall use a causal bond graph model richer in information and to which we shall apply what we called in former articles: the analytical procedure of the scattering parameters exploitation with the aim of showing the importance of the causality notion in the physical systems study by the bond graph approach, as well as the importance of the ways and causal loops notion. Results: We will, initially, apply this discussion, to an elementary transmission line; in the second place, the application is carried out on the equivalent circuit of a band pass filter based on localized elements often used like microwave filters in high frequencies studies. Conclusion: We will finish this discussion by realizing the scattering bond graph model of a quadruple by pointing out the procedure used for the construction of this new type of bond graph model.
\end{abstract}

Key words: Transmission line, scattering bond graph model, bond pass filter, loops notion, microwave filters, graph technique, dynamic behavior, physical systems

\section{INTRODUCTION}

The development of the bond graph technique was articulated around two basic concepts which are the reticulation assumption and the power continuity principle (Mota and Mota, 2011), without forgetting the importance of the causality concept, which reveals the relations of cause for purpose (Cause with effect) between the various modules of the system and returns the bond graph model richer in information than a simple graph model (Birkett, 2009).

The profits of the causal ways and loops make it possible, amongst other things, to make structural analysis, to have an estimate on the dynamic behavior of the system, to determine the Inputs-outputs relations, whereas the scattering formalism, through its different properties evoked previously (Taghouti and Mami, 2010a; Taghouti and Mami, 2009), includes explicitly the conservation laws and respect in an intrinsic way the causal relations (Buisson et al, 2000). It thus plays a significant role in the bond graph development and add the interest which Paynter (1992) grants to him which regards it as an alternative approach for the physical systems modeling.

We will trying, in this article, to apply the new modeling technique, described in former articles, which uses collectively the scattering formalism and the bond graph approach for a modeling of the physical systems often working in high frequencies. For that purpose and although these works on this new technique remain limited at least as regards the bond-graphic designers, the display of what was made in this domain will allow us to propose, at the beginning of our researches, a method based on a non-causal (acausal) bond graph to calculate the scattering matrix of the studied system.

Then and while basing itself on the fact that the concept of causality is a concept very significant in

Corresponding Author: Hichem Taghouti, Department of Electrical Engineering, Laboratory of Analysis and Command Systems,

E.N.I.T - BP 37, 1002 Tunis Le BELVEDERE, Tunisia Tel: + 21699977532

459 
modeling of the physical systems since it enables us to organize the relations constitutive of the elements in an Inputs-outputs form and to analyze the variables of powers effort and flow in terms of dependence, we propose in the continuation of this study to build the "Scattering Bond Graph" model by taking account of the causality concept contrary with what was carried out in the study of Professor (Kamel and DauphinTanguy, 1996) which completely cancelled the concept of causality in spite of its importance. We consider, for the construction of this new model, as starting point the conventional bond graph model which will enable us to calculate the scattering parameters by the application of the analytical exploitation procedure explained in our previously papers and which uses the causal ways notions and the Masson rule applied to the transformed, reduced and causal bond graph model and for objective to apply to the found scattering matrix, which is not actually a transfer matrix, the procedure described in the previously papers (Taghouti and Mami, 2010a) in order to have the famous model "Scattering Bond Graph" of the studied system.

Calculation of the scattering matrix from a noncausal (acausal) bond graph representation: The starting point of this method is the acausal bond graph of a physical or electrical studied system brought back in the elementary shape to two branches including only one "0-junction" and " 1 -junction" associated with an equivalent impedance and admittance in cascades (Kamel et al., 1993).

Now let us consider the series impedance and the parallel admittance in reduced variables as the Fig. 1a and Fig. 1b shows it below.

$\mathrm{w}_{\mathrm{i}}=\frac{\mathrm{v}+\mathrm{i}}{2}$

$\mathrm{w}_{\mathrm{r}}=\frac{\mathrm{v}-\mathrm{i}}{2}$

The bond graph representations (Fig. 2) associated respectively to the Fig. 1a and $\mathrm{b}$ above will be as follows:

The scattering matrices $S_{\text {series }}$ (often noted $S_{\mathrm{s}}$ ) and $S_{\text {parallel }}$ (often noted $S_{p}$ ) associated to the two representations below can be written, while being based with the Eq. 1 and 2 and with the Kirchhoff rules, in the following form Eq. 3 and 4:

$$
S_{s}=\left[\begin{array}{cc}
\frac{z}{z+2} & \frac{2}{z+2} \\
\frac{2}{z+2} & \frac{z}{z+2}
\end{array}\right]
$$

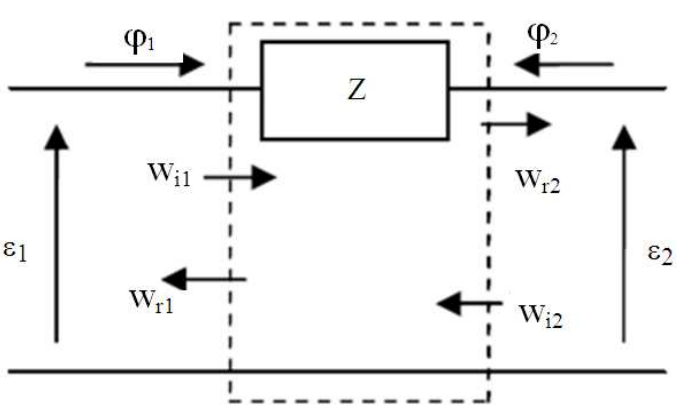

(a)

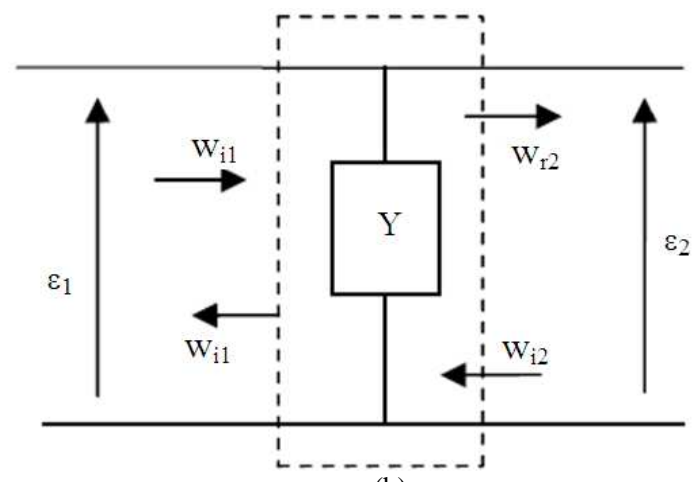

(b)

Fig. 1: (a) Series impedance in reduced variables (b) Parallel admittance in reduced variables

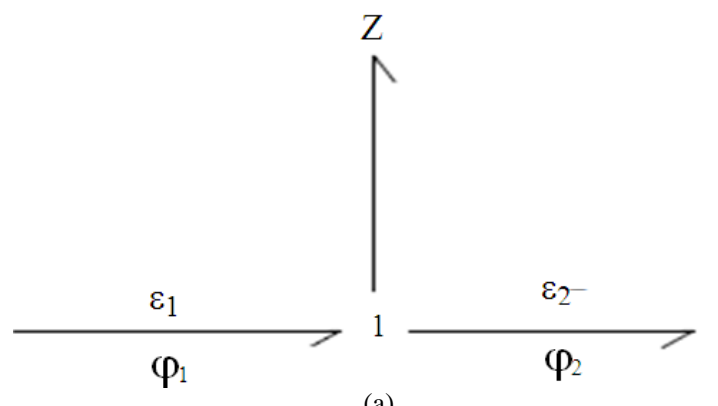

(a)

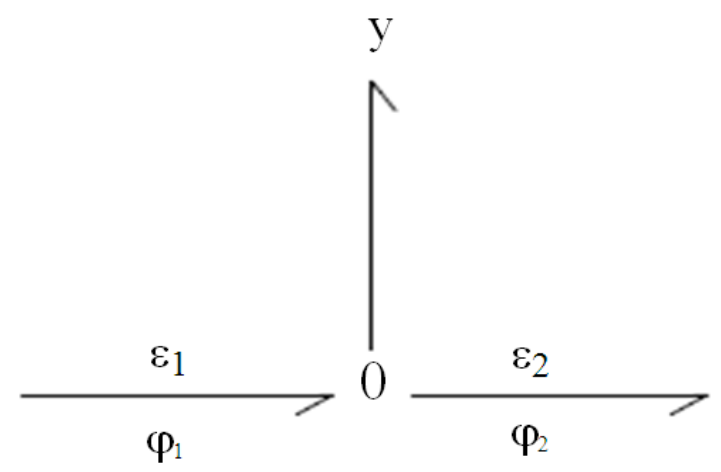

Fig. 2: (a) The acausal bond graph associated to Fig. 1a (b) The acausal bond graph associated to Fig. 1b 
Am. J. Applied Sci., 9 (4): 459-467, 2012

$S_{p}=\left[\begin{array}{cc}\frac{-y}{y+2} & \frac{2}{y+2} \\ \frac{2}{y+2} & \frac{-y}{y+2}\end{array}\right]$

The equivalence out of wave matrixes is given respectively by the below expressions Eq. 5 and 6:

$$
\begin{aligned}
& \mathrm{W}_{\mathrm{s}}=\left[\begin{array}{cc}
\frac{\mathrm{z}+2}{2} & -\frac{\mathrm{z}}{2} \\
\frac{\mathrm{z}}{2} & \frac{2-\mathrm{z}}{2}
\end{array}\right] \\
& \mathrm{W}_{\mathrm{p}}=\left[\begin{array}{cc}
\frac{\mathrm{y}+2}{2} & \frac{\mathrm{y}}{2} \\
-\frac{\mathrm{y}}{2} & \frac{2-\mathrm{y}}{2}
\end{array}\right]
\end{aligned}
$$

The product of the two wave matrixes below gives us the total wave matrix $\mathrm{W}_{\mathrm{sp}}$ of the system in cascade in the following form Eq. 7:

$$
\mathrm{W}_{\mathrm{sp}}=\mathrm{W}_{\mathrm{s}} \cdot \mathrm{W}_{\mathrm{p}}=\left[\begin{array}{cc}
\frac{\mathrm{zy}+\mathrm{z}+\mathrm{y}+2}{2} & \frac{\mathrm{zy}-\mathrm{z}+\mathrm{y}}{2} \\
\frac{\mathrm{zy}+\mathrm{z}-\mathrm{y}}{2} & \frac{\mathrm{zy}-\mathrm{z}-\mathrm{y}+2}{2}
\end{array}\right]
$$

By applying the transformations between wave matrixes and scattering matrixes, we can have the total scattering matrix form $S_{\mathrm{sp}}$ of the system in cascade, such as Eq. 8:

$$
\mathrm{S}_{\mathrm{sp}}=\frac{1}{\mathrm{zy}+\mathrm{z}+\mathrm{y}+2}\left[\begin{array}{cc}
\mathrm{zy}+\mathrm{z}-\mathrm{y} & 2 \\
2 & -\mathrm{zy}+\mathrm{z}-\mathrm{y}
\end{array}\right]
$$

The determination of the scattering matrix of a complex physical system is made by referring to the Eq. 8 and by the organization of the system in the hierarchical arborescence form allowing finding the elementary structure of equivalent impedance and admittance in cascade (stunt). Now in the case of the electric systems working in high frequencies, the organization in the hierarchical arborescence form is almost impossible, because, like example, we can never return an antenna with micro-strip lines or multi-coats (multilayer) antennas with distributed elements under the shape of serial impedance in cascade (stunt) with a parallel admittance. We shall discuss during this study the case of the characteristic impedances of these systems and the possibilities of returning them in the form of impedance and admittance in cascade (stunt).

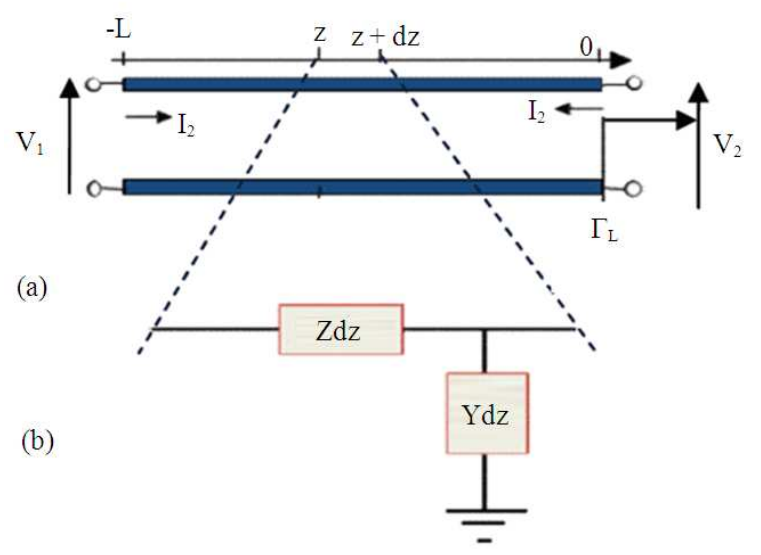

Fig. 3: (a) Transmission line; (b) Elementary line variation

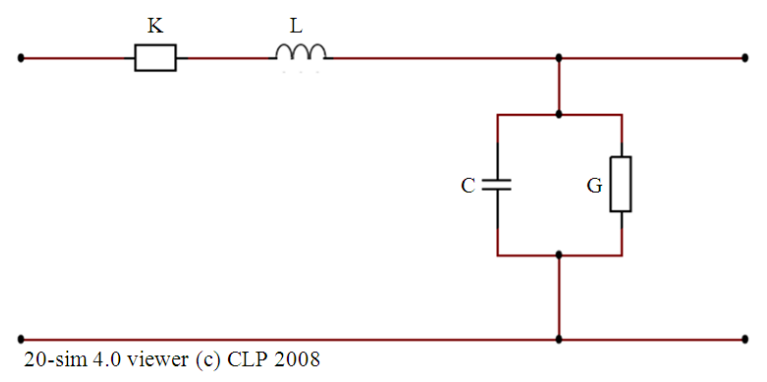

Fig. 4: Quadripolar representation of a linear variation with losses

Comparison to the analytical exploitation procedure: Application in a transmission elementary line: Let us consider now the transmission line and its elementary variation represented like indicates it the following Fig. 3.

The electric study of the transmission lines (Beck et al., 1995) is possible that has to leave an equivalent model with localized elements and which represents a linear variation which the dimensions are much smaller than the used wavelength guided $(1<<\lambda)$. Under these constraints, it is possible to model the line as a stake in cascade (stunt) of elementary quadripole (Matthaei et al., 1980) as indicates it the Fig. 4 below.

Where:

$\mathrm{R}=$ Linear electrical resistance

$\mathrm{L}=$ Linear inductance

$\mathrm{C}=$ Linear capacity

$\mathrm{G}=$ Linear conductance

The elementary structure of the equivalent linear impedance and linear admittance in cascade is given by the following expressions Eq. 9: 
$\left\{\begin{array}{l}\mathrm{Z}=\mathrm{R}+\mathrm{jLw} \\ \mathrm{Y}=\mathrm{G}+\mathrm{jCw}\end{array}\right.$

The normalization of these expressions compared to a normalization resistance (often we shall consider the internal resistance of the generator as normalization resistance by taking into accounts the condition of impedance adaptation) allows us to write Eq. 10 and 11:

$\left\{\begin{array}{l}z=r+\tau_{L} \cdot s \\ y=g+\tau_{C} \cdot s\end{array}\right.$

Where:

$$
\left\{\begin{array}{l}
r=\frac{R}{R_{0}}, g=\frac{1}{r} \\
\tau_{L}=\frac{L}{R_{0}}, \tau_{C}=C \cdot R_{0}
\end{array}\right.
$$

From the acausal bond graph model of Fig. 5 given below as well as the expression of Eq. 8, we can directly deduce the scattering parameters of the elementary line variation describes previously.

Thus we can write Eq. 12:

$$
\left\{\begin{array}{l}
\mathrm{S}_{11}=\frac{\tau_{\mathrm{C}} \tau_{\mathrm{L}} \cdot \mathrm{s}^{2}+\left[\begin{array}{c}
\tau_{\mathrm{L}}(1+\mathrm{g})- \\
\tau_{\mathrm{C}}(1-\mathrm{r})
\end{array}\right] \cdot \mathrm{s}+\mathrm{g}(\mathrm{r}-1)+\mathrm{r}}{\tau_{\mathrm{C}} \tau_{\mathrm{L}} \cdot \mathrm{s}^{2}+\left[\begin{array}{c}
\tau_{\mathrm{C}}(1+\mathrm{r})+ \\
\tau_{\mathrm{L}}(1+\mathrm{g})
\end{array}\right] \cdot \mathrm{s}+\mathrm{r}(1+\mathrm{g})+\mathrm{g}+2} \\
\mathrm{~S}_{12}=\frac{2}{\tau_{\mathrm{C}} \tau_{\mathrm{L}} \cdot \mathrm{s}^{2}+\left[\begin{array}{c}
\tau_{\mathrm{C}}(1+\mathrm{r})+ \\
\tau_{\mathrm{L}}(1+\mathrm{g})
\end{array}\right] \cdot \mathrm{s}+\mathrm{r}(1+\mathrm{g})+\mathrm{g}+2} \\
\mathrm{~S}_{21}=\frac{2}{\tau_{\mathrm{C}} \tau_{\mathrm{L}} \cdot \mathrm{s}^{2}+\left[\begin{array}{c}
\tau_{\mathrm{C}}(1+\mathrm{r})+ \\
\tau_{\mathrm{L}}(1+\mathrm{g})
\end{array}\right] \cdot \mathrm{s}+\mathrm{r}(1+\mathrm{g})+\mathrm{g}+2} \\
\mathrm{~S}_{22}=\frac{-\tau_{\mathrm{C}} \tau_{\mathrm{L}} \cdot \mathrm{s}^{2}-\left[\begin{array}{l}
\tau_{\mathrm{C}}(1+\mathrm{r})+ \\
\tau_{\mathrm{L}}(\mathrm{g}-1)
\end{array}\right] \cdot \mathrm{s}-\mathrm{g}(\mathrm{r}+1)+\mathrm{r}}{\tau_{\mathrm{C}} \tau_{\mathrm{L}} \cdot \mathrm{s}^{2}+\left[\begin{array}{l}
\tau_{\mathrm{C}}(1+\mathrm{r})+ \\
\tau_{\mathrm{L}}(1+\mathrm{g})
\end{array}\right] \cdot \mathrm{s}+\mathrm{r}(1+\mathrm{g})+\mathrm{g}+2}
\end{array}\right.
$$

To apply the analytical exploitation procedure which takes account of the causality concept, we start by assigning an integral causality on the bond graph above while supposing that the linear and reduced impedance and admittance have respectively the characteristics of an inductance and a capacity. From where the causal and reduced bond graph model of the linear variation will be like the Fig. 6 indicates it below.

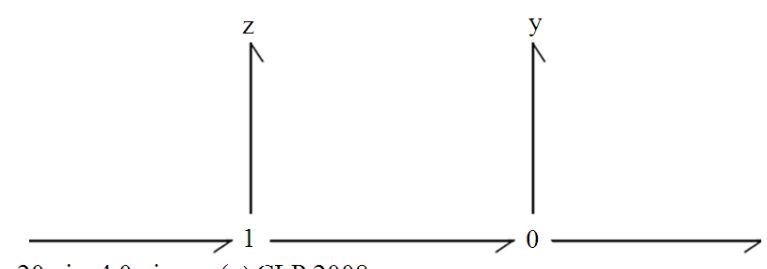

$20-\operatorname{sim} 4.0$ viewer (c) CLP 2008

Fig. 5: The acausal bond graph model of the linear variation with losses

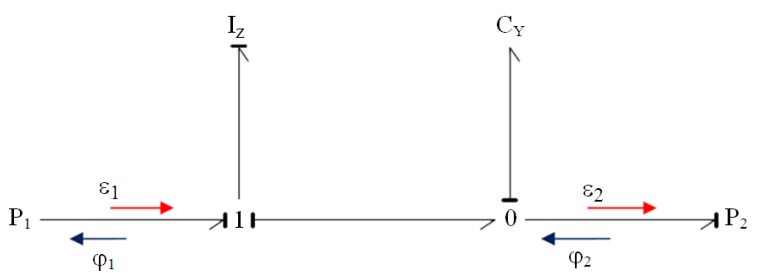

Fig. 6: The causal and reduced bond graph model of the linear variation

The causality assignment on this bond graph results in an effort-flow causality seen by the system as indicated on Fig. 6. While referring to our old works (Taghouti and Mami, 2009; 2010a; 2010b), the analytical Inputs-outputs relations can take, then, the following form Eq. 13:

$$
\left\{\begin{array}{l}
\varphi_{1}(\mathrm{t})=\mathrm{H}_{11}(\mathrm{~s}) \varepsilon_{1}(\mathrm{t})+\mathrm{H}_{12}(\mathrm{~s}) \varphi_{2}(\mathrm{t}) \\
\varepsilon_{2}(\mathrm{t})=\mathrm{H}_{21}(\mathrm{~s}) \varepsilon_{1}(\mathrm{t})+\mathrm{H}_{22}(\mathrm{~s}) \varphi_{2}(\mathrm{t})
\end{array}\right.
$$

The scattering matrix will take the following form Eq. 14:

$$
\left\{\begin{array}{l}
\mathrm{S}=\frac{1}{1+\mathrm{H}_{11}-\mathrm{H}_{22}+\Delta \mathrm{H}}\left[\begin{array}{cc}
1-\mathrm{H}_{11}-\mathrm{H}_{22} & 2 \mathrm{H}_{12} \\
-\Delta \mathrm{H} & -1-\mathrm{H}_{11} \\
-2 \mathrm{H}_{21} & -\mathrm{H}_{22}+\Delta \mathrm{H}
\end{array}\right] \\
\Delta \mathrm{H}=\mathrm{H}_{11} \mathrm{H}_{22}-\mathrm{H}_{12} \mathrm{H}_{21}
\end{array}\right.
$$

We detect, on this reduced and causal bond graph model, by going through the causal ways, a single causal loop $B_{1}$ where the associated integro-differential operator is Eq. 15:

$\mathrm{B}_{1}=\frac{1}{\mathrm{z} \cdot \mathrm{y}}$ 
The integro-differential operator associated with the determiner of the reduced bond graph model is Eq. 16:

$$
\Delta=1-\frac{1}{\mathrm{z} \cdot \mathrm{y}}
$$

The operator associated with the causal way connecting the reduced variable $\varepsilon_{1}$ with the $P_{1}$ port to the variable $\varphi_{1}$ with the same port is Eq. 17:

$$
\mathrm{H}_{11}(\mathrm{~s})=\frac{\mathrm{y}}{\mathrm{z} \cdot \mathrm{y}-1}
$$

The operator associated with the causal way connecting the reduced variable $\varphi_{2}$ with the $P_{2}$ port to the variable $\varphi_{1}$ with the $\mathrm{P}_{1}$ port is Eq. 18:

$$
\mathrm{H}_{12}(\mathrm{~s})=\frac{1}{\mathrm{z} \cdot \mathrm{y}-1}
$$

The operator associated with the causal way connecting the reduced variable $\varepsilon_{1}$ with the $\mathrm{P}_{1}$ port to the variable $\varepsilon_{2}$ with the $\mathrm{P}_{2}$ port is Eq. 19:

$$
\mathrm{H}_{21}(\mathrm{~s})=\frac{-1}{\mathrm{z} \cdot \mathrm{y}-1}
$$

The operator associated with the causal way connecting the reduced variable $\varphi_{2}$ with the $\mathrm{P}_{2}$ port to the variable $\varepsilon_{2}$ with the same port is Eq. 20:

$$
\mathrm{H}_{22}(\mathrm{~s})=\frac{-\mathrm{z}}{\mathrm{z} \cdot \mathrm{y}-1}
$$

While referring to Eq. 14, the scattering parameters of the $S$ matrix according to the linear reduced impedance and admittance are such as Eq. 21:

$\left\{\begin{array}{l}S_{11}=\frac{z \cdot y-y+z}{z \cdot y+y+z-2} \\ S_{12}=\frac{2}{z \cdot y+y+z-2} \\ S_{21}=\frac{2}{z \cdot y+y+z-2} \\ S_{22}=\frac{-z \cdot y-y+z}{z \cdot y+y+z-2}\end{array}\right.$

By replacing the linear impedance and admittance by their Eq. 10, we can rewrite the scattering parameters in the following form Eq. 22:

$$
\left\{\begin{array}{l}
S_{11}=\frac{\tau_{\mathrm{C}} \tau_{\mathrm{L}} \cdot \mathrm{s}^{2}+\left[\begin{array}{l}
\tau_{\mathrm{L}}(1+\mathrm{g})+ \\
\tau_{\mathrm{C}}(\mathrm{r}-1)
\end{array}\right] \cdot \mathrm{s}+\mathrm{r}(\mathrm{g}+1)-\mathrm{g}}{\tau_{\mathrm{C}} \tau_{\mathrm{L}} \cdot \mathrm{s}^{2}+\left[\begin{array}{l}
\tau_{\mathrm{C}}(1+\mathrm{r})+ \\
\tau_{\mathrm{L}}(1+\mathrm{g})
\end{array}\right] \cdot \mathrm{s}+\mathrm{r}(1+\mathrm{g})+\mathrm{g}-2} \\
\mathrm{~S}_{12}=\frac{2}{\tau_{\mathrm{C}} \tau_{\mathrm{L}} \cdot \mathrm{s}^{2}+\left[\begin{array}{l}
\tau_{\mathrm{C}}(1+\mathrm{r})+ \\
\tau_{\mathrm{L}}(1+\mathrm{g})
\end{array}\right] \cdot \mathrm{s}+\mathrm{r}(1+\mathrm{g})+\mathrm{g}-2} \\
\mathrm{~S}_{21}=\frac{2}{\tau_{\mathrm{C}} \tau_{\mathrm{L}} \cdot \mathrm{s}^{2}+\left[\begin{array}{l}
\tau_{\mathrm{C}}(1+\mathrm{r})+ \\
\tau_{\mathrm{L}}(1+\mathrm{g})
\end{array}\right] \cdot \mathrm{s}+\mathrm{r}(1+\mathrm{g})+\mathrm{g}-2} \\
\mathrm{~S}_{22}=\frac{-\tau_{\mathrm{C}} \tau_{\mathrm{L}} \cdot \mathrm{s}^{2}+\left[\begin{array}{c}
\tau_{\mathrm{L}}(1-\mathrm{g}) \\
-\tau_{\mathrm{C}}(1+\mathrm{r})
\end{array}\right] \cdot \mathrm{s}+\mathrm{r}(1-\mathrm{g})-\mathrm{g}}{\tau_{\mathrm{C}} \tau_{\mathrm{L}} \cdot \mathrm{s}^{2}+\left[\begin{array}{l}
\tau_{\mathrm{C}}(1+\mathrm{r}) \\
+\tau_{\mathrm{L}}(1+\mathrm{g})
\end{array}\right] \cdot \mathrm{s}+\mathrm{r}(1+\mathrm{g})+\mathrm{g}-2}
\end{array}\right.
$$

We notice that the scattering parameters found by the two methods present some differences with regard to the sign of the numerator or the denominator parameters, which is due to the causality assignment and the change number of the orientation while following the variables efforts and flow through the information bonds of the reduced and causal bond graph model above.

Discussion and comment: The causality assignment on a bond graph model does not depend solely on the type of elements but also on the total structure of junction. In fact, the causality is more informative than the concept of impedance and admittance (Birkett, 2009) which loses of its interest on a bond graph model replaced by the concept of elementary transmittance obtained starting from the profits of the ways and the causal loops.

Moreover, with regard to the extraction of the scattering parameters method by the analytical exploitation procedure describes in our previously works (Taghouti and Mami, 2010a), where we presented the four relations related to the various types of causality, making it possible to determine the $S$ matrix. The problem arises when one deals with situation where causality on the bond of entry, the bond of exit or even on the two bonds is not single. In this case, the choice of the type of causality determines which relations to be used (Taghouti and Mami, 2009; 2010a; 2010b).

However, it would be more judicious, to facilitate and reduce calculations, to choose the case of the obligatory causality imposed by the inductive and capacitive elements constituting the studied system and 
if is not the case, choosing us causality making revealing a minimum number of ways and causal loops as in the case of the example of the elementary line variation of the previously Fig. 6.

Otherwise, in the method of the acausal bond graph which allows us, after a hierarchical reorganization, to obtain an impedance series and a parallel admittance in cascades about it (Redfield and Krishnan, 1993) and by looking at the Ohm's law given by the Eq. 23 above for the calculation of impedance, we note that a causality entering effort (or outgoing flow) was implicitly taken into account resulting in a derived causality for elements I and one integral causality for the elements CL:

$$
\mathrm{U}=\mathrm{Z} \cdot \mathrm{I} \Rightarrow\left\{\begin{array}{l}
\mathrm{U}=\mathrm{R} \cdot \mathrm{I} \\
\mathrm{U}=\tau_{\mathrm{L}} \cdot \mathrm{s} \cdot \mathrm{I} \\
\mathrm{U}=\frac{1}{\tau_{\mathrm{C}} \cdot \mathrm{s}} \cdot \mathrm{I}
\end{array}\right.
$$

Reciprocally, in the calculation of admittance, in fact the "I" elements are in integral causality whereas the "C" elements are in derived causality. This being well cavity, independent from the effective causality which would have the bond graph model in integral causality.

\section{MATERIALS AND METHODS}

Realization procedure of the scattering bond graph: We propose, during this article, a new type of relation enters the scattering formalism and the bond graph approach while combining both procedures described during our research works (Taghouti and Mami, 2010b; Taghouti and Mami, 2009; ), by leaving from a reduced and causal bond graph model (Amara and Scavarda, 1991) to reach a particular type of bond graph model called "Scattering bond graph" who makes to appear explicitly the various of power waves (Kamel and Dauphin-Tanguy, 1996; Kamel et al., 1993).

Contrary to the scattering formalism often used in problems of waves distribution (optics, hyperfrequency) (Wake, 1998), a bond graph model is an unified representation by numerous domains of the physics and like the scattering bond graph is associated with a classic bond graph model, we tried, in this article, to preserve our studies in the frequency field while choosing to work like beginning, on highpass filters with localized or distributed elements (Taghouti and Mami, 2009; 2010a; 2010b) considering the realization of this type of bond graph amounts changing field of study while passing from the frequency field to the temporal field.
Scattering bond graph of a quadripole: The most general form of the scattering matrix " $\mathrm{S}$ " of a quadripole is given by the Eq. 24 and 25 below:

$S=\frac{1}{d(s)}\left[\begin{array}{cc}b_{n}^{11} s^{n}+\cdots+b_{0}^{11} & b_{n}^{12} s^{n}+\cdots+b_{0}^{12} \\ b_{n}^{21} s^{n}+\cdots+b_{0}^{21} & b_{n}^{22} s^{n}+\cdots+b_{0}^{22}\end{array}\right]$

Where:

$d(s)=a_{n} s^{n}+a_{n-1} s^{n-1}+\cdots+a_{0}$

The $\mathrm{S}$ matrix presented above is a 2-2-matrix having a particular form whatever the complexity of the expressions of the equivalent series impedance or parallel admittance if we work by an acausal bond graph model (Kamel and Dauphin-Tanguy, 1996; Kamel et al., 1993).

Indeed, if the system does not have any active source, then the quadripole is known as reciprocal, moreover, if the system is supposed without loss the $S$ matrix is orthogonal.

The number of dynamic components present in the studied physical system is given by the " $n$ " degree of $\mathrm{d}(\mathrm{s})$ denominator. Indeed, " $\mathrm{n}$ " will indicate the number of I and C elements in integral causality if one started from a bond graph model, whereas the elements which are in derived causality do not play a part in the dynamics of the system.

\section{RESULTS}

Now let us consider the equivalent circuit of a band-pass filter based on localized elements like the Fig. 7 shows it below.

The conventional and causal bond graph model of this filter intercalated between the two input-output ports $\mathrm{P}_{1}$ and $\mathrm{P}_{2}$ is given by the Fig. 8 .

We know that in such circuit the two parallel and series inductive and capacitive elements, like the Fig. 8 indicates it above, can be replaced by an impedance series and a parallel admittance without modifying the dynamic behavior of the system. To apply the analytical exploitation procedure to the $\mathrm{S}$ scattering matrix, we simplify the model above in a transformed, causal and reduced bond graph model as indicates it the following Eq. 26 Fig. 9.

Where:

$$
\left\{\begin{array}{l}
z=\frac{1}{\tau_{\mathrm{C} 1} \mathrm{~s}}+\tau_{\mathrm{L} 1} \mathrm{~s} \\
\mathrm{y}=\tau_{\mathrm{C} 2} \mathrm{~s}+\frac{1}{\tau_{\mathrm{L} 2} \mathrm{~s}}
\end{array}\right.
$$


Am. J. Applied Sci., 9 (4): 459-467, 2012

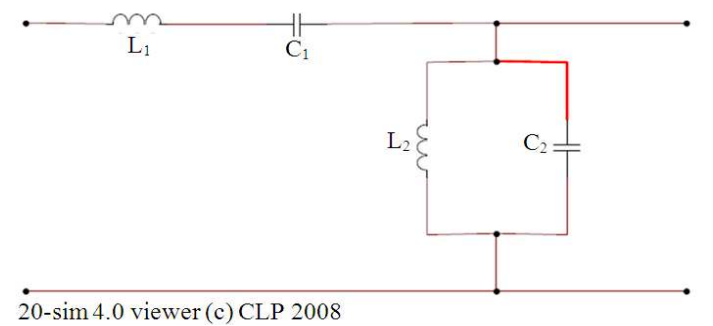

Fig. 7: Equivalent Circuit of the band-pass filer

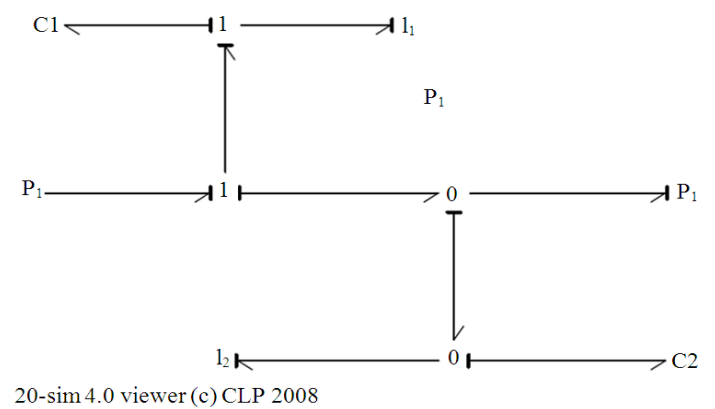

Fig. 8: Conventional and causal bond graph model of the band-pass filter

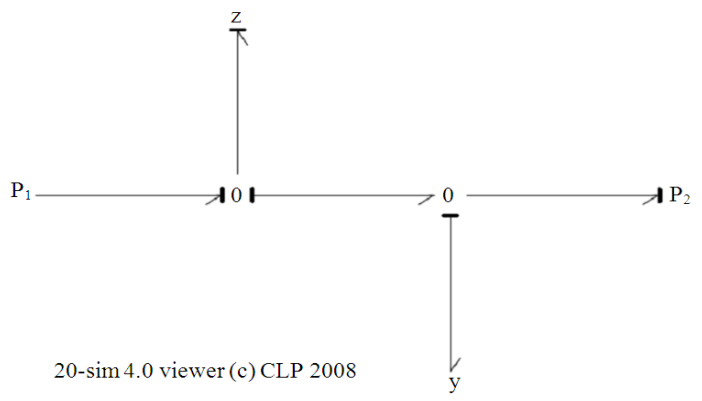

Fig. 9: Reduced and causal bond graph model of the studied filter

The parameters of the scattering matrix will be thus in the following forms:

$$
\begin{aligned}
& \tau_{\mathrm{L} 1} \tau_{\mathrm{L} 2} \tau_{\mathrm{C} 1} \tau_{\mathrm{C} 2} \mathrm{~s}^{4}+\tau_{\mathrm{C} 1} \tau_{\mathrm{L} 2}\left(\tau_{\mathrm{L} 2}-\tau_{\mathrm{C} 2}\right) \mathrm{s}^{3} \\
& \mathrm{~S}_{11}=\frac{+\left(\tau_{\mathrm{C} 2}{ }^{\tau} \mathrm{L} 2{ }^{+}{ }_{\mathrm{L} 1}{ }^{\tau} \mathrm{C} 1\right) \mathrm{s}^{2}+\left(\tau_{\mathrm{L} 2}-{ }_{\mathrm{C} 1}\right) \mathrm{s}+1}{{ }_{\mathrm{L} 1} \tau_{\mathrm{L} 2}{ }^{\tau}{ }_{\mathrm{C} 1}{ }^{\tau}{ }_{\mathrm{C} 2} \mathrm{~s}^{4}+{ }_{\mathrm{C} 1} \tau_{\mathrm{L} 2}\left({ }_{\mathrm{C} 2}+{ }_{\mathrm{L} 1}\right) \mathrm{s}^{3}+} \\
& \left(\tau_{\mathrm{C} 2} \tau_{\mathrm{L} 2}+\tau_{\mathrm{L} 1} \tau_{\mathrm{C} 1}+2 \tau_{\mathrm{L} 2} \tau_{\mathrm{C} 1}\right) \mathrm{s}^{2}+\left(\tau_{\mathrm{C} 1}+\tau_{\mathrm{L} 2}\right) \mathrm{s}+1 \\
& \mathrm{~S}_{12}=\frac{{ }^{2 \tau}{ }_{\mathrm{C} 1} \tau_{\mathrm{L} 2} \mathrm{~s}^{2}}{\tau_{\mathrm{L} 1} \tau_{\mathrm{L} 2}{ }^{\tau} \mathrm{C} 1{ }^{\tau} \mathrm{C} 2^{\mathrm{s}^{4}+{ }_{\mathrm{C} 1}{ }^{\tau} \mathrm{L} 2}\left({ }_{\mathrm{C} 2}+\tau_{\mathrm{L} 1}\right) \mathrm{s}^{3}+}
\end{aligned}
$$

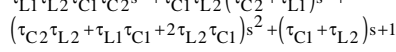

$$
\begin{aligned}
& \mathrm{S}_{12}=\frac{{ }^{2}{ }_{\mathrm{C} 1}{ }_{\mathrm{L} 2} \mathrm{~s}^{2}}{\tau_{\mathrm{L} 1} \tau_{\mathrm{L} 2}{ }^{\tau} \mathrm{C} 1{ }^{\tau} \mathrm{C} 2 \mathrm{~s}^{4}+\tau_{\mathrm{C} 1}{ }^{\tau} \mathrm{L} 2\left({ }_{\mathrm{C} 2}+\tau_{\mathrm{L} 1}\right) \mathrm{s}^{3}+} \\
& \left(\tau_{\mathrm{C} 2} \tau_{\mathrm{L} 2}+\tau_{\mathrm{L} 1} \tau_{\mathrm{C} 1}+2 \tau_{\mathrm{L} 2}{ }^{\tau} \mathrm{C} 1\right) \mathrm{s}^{2}+\left(\tau_{\mathrm{C} 1}+\tau_{\mathrm{L} 2}\right) \mathrm{s}+1 \\
& { }^{-} \tau_{\mathrm{L} 1} \tau_{\mathrm{L} 2}{ }^{\tau} \mathrm{C} 1{ }^{\tau}{ }_{\mathrm{C} 2} \mathrm{~s}^{4}+\tau_{\mathrm{C} 1} \tau_{\mathrm{L} 2}\left(\tau_{\mathrm{L} 1}-\tau_{\mathrm{C} 1}\right) \mathrm{s}^{3}
\end{aligned}
$$

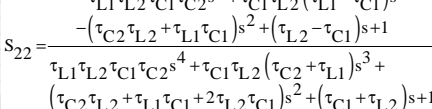

\section{DISCUSSION}

This matrix is not a true transfer matrix (contrary to the wave matrix), we will precede it like that, at least from an input-output point of view, connecting, in a symbolic form, the incident and reflected waves. With this intention, we will apply the results of the previously works (Taghouti and Mami, 2009; 2010a; 2010b) which makes it possible to build a bond graph model starting from a transfer function or matrix (Kamel and Dauphin-Tanguy, 1996; Kamel et al., 1993).

The $\mathrm{S}$ matrix is not in an adequate form since the degree of the numerator is equal to that of the denominator. The step to be followed thus consists in carrying out the Euclidian division of each term of the matrix numerator by the common denominator $\mathrm{d}(\mathrm{s})$ what gives a new matrix noted S" having a degree to the numerator equal to that of the denominator $\mathrm{d}(\mathrm{s})$ decreased by one.

The new form of the scattering matrix, after the Euclidian division, will be in the following form Eq. 28:

$\mathrm{S}=\mathrm{S}^{\prime}+\mathrm{M}_{\mathrm{D}}$

$M_{D}=$ Represent the direct transmission matrix.

The terms of the constant matrix $\mathrm{M}_{\mathrm{D}}$ are a function of the respective coefficients of the numerators and the common denominator thus represent the quotients of Euclidian division of the each term of the scattering matrix by its common denominator (Kamel and Dauphin-Tanguy, 1996; Kamel et al., 1993).

It will, thus, take the following form Eq. 29:

$M_{D}=\left[\begin{array}{ll}q_{11} & q_{12} \\ q_{21} & q_{22}\end{array}\right]$

The second stage consists in seeking for the new scattering matrix " $\mathrm{S}$ " the development in alpha-beta and building the corresponding bond graph model by using the procedure of realization of a bond graph model in the multivariable case like we explained in the previously papers.

The direct part comes to be grafted on this bond graph using a suitable number of bonds from information connecting the entries to the various exits.

We represent the scattering bond graph model in the case of a direct diagonal matrix by the following Fig. 10. 


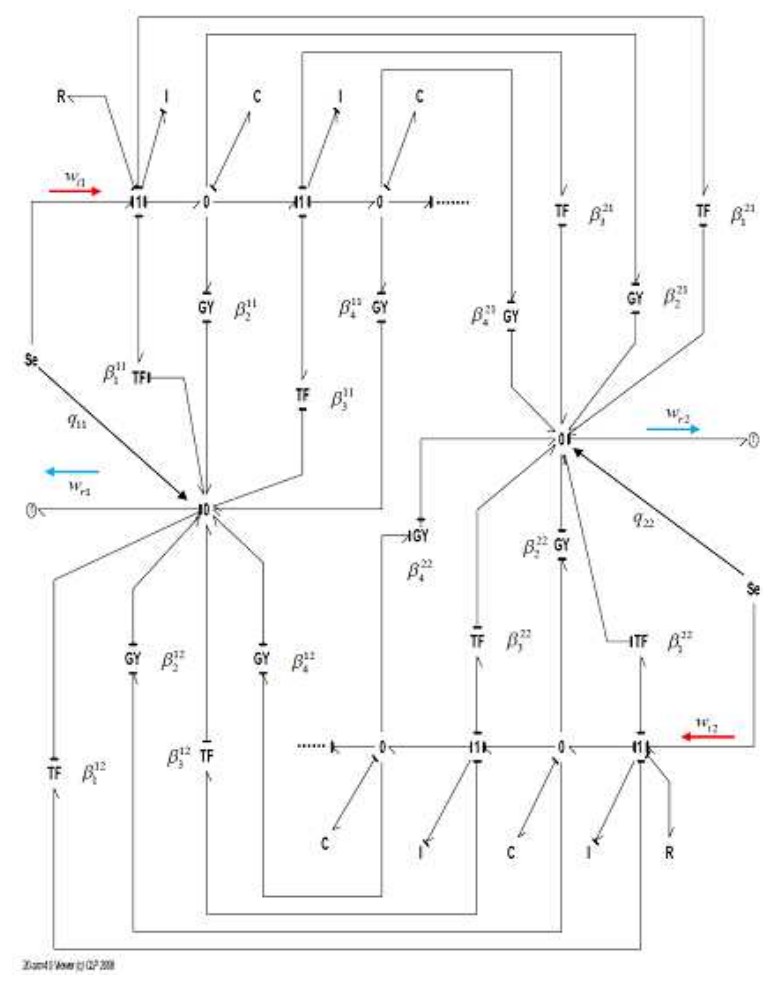

Fig. 10: The scattering bond graph model of the quadripole

This particular type of bond graph, consists of two identical direct chains (the $\mathrm{S}$ matrix of any quadripole is square and has dimension two) modeling the dynamic part (Kamel and Dauphin-Tanguy, 1996) related to the common denominator $\mathrm{d}(\mathrm{s})$ and having for entries two effort sources representing the incidental waves $\mathrm{w}_{\mathrm{r} 1}$ et $\mathrm{w}_{\mathrm{r} 2}$.

The total structure of the bond graph model remains same whatever the degree of the common denominator. Only the number of I and C elements, related to the number of $\alpha_{i}$ and thus with the degree of $\mathrm{d}(\mathrm{s})$, changes. This being, obviously, in accord with the preceding remark on $n$ degree of $d(s)$.

The variables of exit, representing the reflected waves $\mathrm{w}_{\mathrm{r} 1}$ et $\mathrm{w}_{\mathrm{r} 2}$, are obtained using detectors judiciously placed to collect information on the level of the adequate port.

\section{CONCLUSION}

In this study, we reminded and explaining briefly, with some improvements, a procedure which uses collectively and in a clarify way the scattering formalism and the bond graph approach for the modelling of a physical system by bringing to light the power waves and their distributions on a particular type of graph bond often called "Scattering Bond Graph".

The procedure described in this study, has allows us to have a temporal representation with dynamic elements which can have a physical interpretation (performance) and a better analyze of energy phenomena.

This procedure gave us, by means of a graphic representation, an access to the various power waves, contrary to the scattering matrix which remains a formal model difficult to interpret.

\section{ACKNOWLEDGMENT}

We would like to thank especially Prof. MAMI Abdelkader for the time and guidance given throughout the all carried out works, without forgetting the members of the unit of electronics and high frequency circuits and all those who contributed and aided for this study in particularly LACS members (Laboratory of analysis and command systems).

\section{REFERENCES}

Amara, M. and S. Scavarda, 1991. A Procedure to Match Bond Graph and Scattering Formalisms. J. Franklin Inst., 328: 887-899. DOI: 10.1016/00160032(91)90060-G

Beck, S.M., H. Haider and R.F. Boucher, 1995. Transmission line modelling of simulated drill strings undergoing water-hammer. Proc. Inst. Mech. Eng. Part C. Mech. Eng. Sci., 209: 419-427.

Birkett, S.H., 2009. Directed bondgraphs and integral matroids. Simulation Model. Practice Theory, 17: 50-68. DOI: 10.1016/j.simpat.2008.04.003

Buisson, J., H. Cormerais and P.Y. Richard, 2000. Using trees to build non-singular bond graphs from electric circuit graphs . J. Franklin Inst., 337: 543554. DOI: 10.1016/S0016-0032(00)00023-5

Kamel, A. and G. Dauphin-Tanguy, 1996. Power transfer in physical systems using the scattering bond graph and a parametric identification approach. Syst. Anal. Model. Simul., 27 : 1-13.

Kamel, A., C. Sueur and G. Dauphin-Tanguy, 1993. How to derive a bond graph model from a transfer matrix. J. Franklin Inst., 330: 787-798. DOI: 10.1016/0016-0032(93)90077-8

Matthaei, G.L., L. Young and E.M.T. Jones, 1980. Microwave filters, impedance-matching networks, and coupling structures. 1st Edn., Artech House Books, Dedham, ISBN-10: 0890060991, pp: 1096. 
Mota, A.A. and L.T.M. Mota, 2011. Drawing Meshed One-Line Diagrams of electric power systems using a modified controlled spring embedder algorithm enhanced with geospatial data. J. Comput. Sci., 7: 234-241. DOI: 10.3844/jcssp.2011.234.241

Paynter, H.M., 1992. An Epistemic Prehistory of Bond Graphs. In: Interesting Historic Perspective by the Inventor Himself, Breedveld, P.C. and G. DauphinTanguy (Eds.). Bond Graphs for Engineers, Elsevier, Amsterdam, pp: 3-17.

Redfield, R.C. and S. Krishnan, 1993. Dynamic System Synthesis with a Bond Graph Approach: Part ISynthesis of one-Port Impedances. J. Dyn. Syst. Meas. Control, 115: 357. DOI: 10.1115/1.2899110

Taghouti, H. and A. Mami, 2009. Application of the reduced bond graph approaches to determinate the scattering parameters of a high frequency filter. Proceedings of the 10th International Conference on Sciences and Techniques of Automatic Control and Computer Engineering, (STACCE' 2009), Academic Publication Center Tunisia, Hammamet Tunisia, pp: 379-391.
Taghouti, H. and A. Mami, 2010a. Extraction, Modelling and Simulation of the Scattering Matrix of a Chebychev Low-Pass Filter with cut-off frequency $100 \mathrm{MHz}$ from its Causal and Decomposed Bond Graph Model. ICGST Int. J. Automatic Control Syst. Eng., 10: 29-37.

Taghouti, H. and A. Mami, 2010b. Modeling method of a low-pass filter based on microstrip T-lines with cut-off frequency $10 \mathrm{GHz}$ by the extraction of its wave-scattering parameters from its causal bond graph model. Am. J. Eng. Applied Sci., 3: 631-642. 2010. DOI: 10.3844 /ajeassp.2010.631.642 